\title{
Exploring the phenomenon of 'medical pluralism': A case of Pakistani Muslim Community in the United Kingdom
}

\author{
Qurratulain Nasiruddin* \\ Medical Anthropology, University College London, UK
}

Submission: September 08, 2018; Published: October 22, 2018

"Corresponding author: Qurratulain Nasiruddin, Medical Anthropology, University College London, UK, Tell: 447721612677;

Email: anny.todai@gmail.com

\begin{abstract}
Power and hegemony are phenomenon in the field of medicine as applicable as it is to human beings; however, it is not given much attention. In contrast to increasing tensions between the different forms of medicines, medical pluralism is a concept that appreciates availability of multiple forms of medicine in a health care system to address varying health needs of people. This study investigates the notion of medical pluralism amongst the Pakistani female migrants in London (UK) through exploring their medical choices and the factors determining their choices. After analysing the responses of in-depth interviews with ten female Pakistani immigrants in London, through an anthropological lens, this study argues that the availability of medicine in a health care system is not enough to acclaim medical pluralism. Along with availability, it is important that people have enough knowledge about each form of medicine to make informed choices without any prejudices and/or assumptions. The study also suggests that the understanding of medical phenomenon, such as medical pluralism, requires examining the factors influencing the availability and knowledge of medicine to people. The current study also puts forwards certain recommendations that can assist health professionals to offer medical care in a pluralistic manner.
\end{abstract}

Keywords: Medicine; Phenomenon; Pluralism; Health

\section{Introduction}

Migration plays a key role in the spread, transformation and propagation of medical practices and its knowledge. When moving from a place to another, people do not only take their belongings, but they also transport their values, beliefs and cultural practices with them. This also includes medical and healing practices. There are two popular opinions about the relation between migration and medicine. Firstly, some anthropologists [1,2], suggest that migrants often assimilate within the social culture of their host country and tend to forget, reject or surpass their own traditional medical practices. Perhaps, it is more likely to be observed in situations where the culture and medical system of country overlooks the diversity of values and beliefs possessed by its people. Contrarily, Gans [3], argues that immigrants use their ethnic and traditional practices as a psychological, social and political defence against the dominating culture of the host society. In such situations, the medical practices function as an ethnic marker or an identity of the minority population of migrants [46]. In either case, one may find that there is not a single state or society where every individual follows a uniform medical practice. Usually, there exists 'plurality' in the choices of medical practices at individual levels. The medical choices made by individuals could depend upon factors such as their gender, religion, ethnic origin or society.

This research aims to explore the medical choices made by the female Pakistani migrants living in the United Kingdom (UK). With an assumption that there are multiple medical options available to migrants in the UK, the research evaluates the factors influencing their medical choices. The purpose of this research is to gain an emic understanding of the phenomenon of 'medical pluralism'. Here, medical pluralism refers to the co-existence of multiple medical systems functioning in harmony with one another [7]. The study focused on women for certain reasons: a. The Self-Rated Health (SRH) ratio suggests that the health of women is three times worse than the health of men living in Pakistan [8], and b. There are several studies suggesting Pakistan is a masculine society where women do not get enough opportunities to make decisions in health care [9-13]. For these reasons, the study focuses on the opinions of Pakistani women about making choices in health care. Nonetheless, this limits the scope of the study; thus, the finding cannot be generalized to all the Pakistani migrants living in the UK. 
The study is carried out on the Pakistani population who have migrated to UK in the last fifteen years and settled in the capital city of the country, London. According to the Census of 2011, the population of Pakistani migrants in the UK is the third largest population comprised of around 482,000 people [14]. London is a home to about half of the international migrants in the UK and the Pakistani population constitutes the second largest non-European migrant community in UK [15]. The total population of Pakistanis living in London represents one-fifth of the national Pakistani population [16].

\section{Methodology}

The main data collection tool was in-depth interviews. In total, there were ten participants interviewed in this study. All interviews were semi-structured. Participants were identified through snowball sampling. All the participants were first wave female migrants, which mean that none of their parents or ancestors migrated and settled in the UK. All the research participants got married in Pakistan before moving to the UK. Some participants moved to the UK soon after the marriage as their spouse were already settled in London whereas few travelled with their spouses after marriage for socio-economic reasons. The age of the participants ranges from twenty-six years to forty-five years; and the period of their stay in London range between three to fifteen years.

\section{Literature Review}

\section{Forms of Medicines}

Medicine, conventionally, is categorized into two broad forms namely biomedicine and traditional medicine. Biomedicine is also referring to as 'western' medicine, 'conventional' medicine, 'modern' medicine and 'allopathy' [6]. Because of its global recognition and usage, it is also called as 'cosmopolitan medicine'. It often constitutes the core component of health systems around the world. Its advancement and progression have enabled the world to restore health quality on a global basis. Conversely, traditional medicine includes a broad range of regional and cultural medical practices. It is also referred to as 'complementary and alternative medicine' when used by non-indigenous people. In the opinion of Kayne [6], traditional medicine can also be referred as folk medicine. However, Csordas [4,5] and Brady [17], refute that folk medicine is different from traditional medicine on the fact that knowledge of folk medicine is transmitted orally and often the healers are not trained. Traditional medicine, unlike folk medicine, could function as a medical system officially and professionally.

\section{Traditional medicine in national health policies}

Considering the popularity and demand, many states have incorporated traditional medicine as part of national health systems and policies $[18,19]$. The World Health Organisation (WHO) reports that there are around 45 countries that already involve traditional medicine in their national health policy while 51 countries mentioned to be in the process of developing national policies on traditional medicine [20]. Traditional medicine can become a part of national health policy in two ways. First, it can be 'integrated' in the national health system. This way, biomedicine and traditional medicine both constitute the content of the training and education of medical practitioners. Secondly, biomedicine and traditional medicine can be treated as 'parallel' but separate forms of medicine under the national health care system. Not always, the two forms of medicine exist in harmony under the state regulation which open discussion on the relation of biomedicine to traditional medicine.

\section{Relation of traditional medicine to biomedicine}

There are various opinions about the relation between biomedicine and traditional medicine. According to Kleinman [21] and Ernst [22], the modern medicine and traditional medicine are binary opposites. These two forms of medicine constantly struggle for hegemonic representation in the field of medicine. During this struggle, till now, the traditional medicine is usually marginalized due to its non-scientific nature whereas western medicine is regarded as a learned system of medicine practised by medical experts [22]. Similarly, Baer et al. [23], proposes that biomedicine always enjoys supremacy and extra attention by state comparisons to traditional medicine despite both are allotted official status in national health policies. These opinions got challenge with the emergence of the field of medical anthropology and increasing interest of social scientists in the field of medicine. The ethnographic studies of people brought a realization that, at community level, both medical systems function in harmony; thus, introducing the notion of 'plural medical system' [21,24].

\section{Plural Medical System}

Plural medical system, as mentioned, refers to a health system where various forms of medicine operate but each function in correspondence to another [7]. Ramsey [25], mentions that plurality of medicine is not a new phenomenon. Even in the eighteenth and nineteenth centuries, there were a variety of healers practicing French medicine along with elite medical professionals. Likewise, Kleinman [21], found out that a health system is based upon the following three medical sectors: the professional sector, the folk sector and the popular sector. Each sector treats health problems differently. The professional sector consists of medical practitioners whereas the folk sector is comprised of local healers. The third sector, the popular sector, forms the largest sector which includes lay and non-professional ways of healing an illness at home or within the community.

The co-existence of three sectors explains that people do not always seek medical advices from the medical system of the country. It appears that the primary concern of people is to get cured or healed rather considering the official status of a medicine. As a result, people follow different kinds of medicine whereas the state regulates a certain form of medicine. Medical pluralism, on one hand, tends to respect the individual's preferences by offering a variety of medical choices. On the other hand, this pose challenges to a state for the regulation of more than one medical system. 
There are certain refutations against the concept of medical pluralism. Strathern and Stewart [26], claim that medical pluralism is possible only if all the co-existing medical systems are equally competitive. Nevertheless, it is not the case as biomedicine often takes the central position in a health system whereas traditional medicine complements or supports the function of biomedicine. Ernst [22], argues that the idea of plural medical system overlooks the extensive history and philosophy behind the hegemonic interplay between the two systems. Also, the plurality in medicine endangers to keep a check on various cultural and scientific frameworks and practices on moral grounds. These arguments are further explored in this study. An evaluation of the participant's responses in this study will help to deduce answers of the fore mentioned refutations.

\section{Pakistani Muslim Migrants in The United Kingdom}

The United Kingdom (UK), a multi-ethnic country, is a home of around 1.2 million Muslims. The Muslims constitute about 3 percent of the total population of the UK [27]. Most of the Muslims are from South Asia specifically from Pakistan and Bangladesh. At several occasions, such as the establishment of the British Nationality Act 1948, labour shortage in 1960 and the formation of New Common Wealth countries, the South Asians were welcomed by the government of UK for migration. For this reason, one may observe a high population of Pakistanis, Indians and Bangladeshis living in the UK.

Medical choices available to Pakistani migrants in UK. Pakistani migrants are privileged to rejoice the medical facilities provided by the National Health Services (NHS) of UK. It is the most common way of medical treatment that is employed by all the participants of this study. It is identified, through interviews, that every participant seeks medical advice and help from the NHS; however, the level of dependency on the NHS, the time to access NHS and the level of satisfaction of each participant with NHS vary depending upon certain factors which are explored in this study. The other medical options include herbal medicine and folk remedies. None of the participant has tried any other form of traditional medicine; but they have observed its usage among relatives and other family members.

\section{National Health Services (NHS)}

The NHS was established in 1948 with an ambition to provide free medical services to every individual living in the UK. This organisation regulates hospitals, general practitioners (GP), pharmacies and other health care facilities. It is the prime organisation that looks after the health concerns of the population of the whole country. It promises to provide best services to its people and encourage the staff to give compassionate care without any discrimination. In general, every participant expressed an admiration for the NHS [28]. Specially, because NHS services are free of cost and the standards are maintained by the government whereas medicine and healthcare in Pakistan is an out-of-pocket expenditure as the system is poorly managed. Participants were happy that they did not have to pay for consultation fees and most of the procedures. In addition, none of the participant mentioned that they felt discriminated or mistreated by any staff based on their ethnicity, race, colour or nationality.

However, a concern raised by participants was the unavailability of appointments at the GP. This concern was equally shared by all the participants. Most of the participants think that the reason for delayed care is the insufficient number of staffs resulting unavailability of appointments in GP surgeries and long waiting hours in emergency services at hospitals. The same issue is also voiced by media and public. For instance, Campbell [29], informs that with the shortage of staff, the burden on each employ increases; consequently, they do not attend patients appropriately. The Guardian news (Topping 2013) reported that there are around 300,000 unregulated or unqualified staff working under NHS employed by GPs and Hospital managers on low wages to meet the budget constraints and for gaining profits. As a result, the Care Quality Commission identified that at least one in every ten patients are denied respect and dignity whereas 20 percent of the patients complain about a neglected health care and welfare [29]. Though "the NHS aspires to put patients at the heart of everything it does" (NHS 2013:12); yet the public's verdicts do not match the core principle of the NHS. However, it should be emphasized that the issue of unavailability of appointments is not related to the participants being 'Pakistani' or 'immigrants' rather it's a concern raised by public and the government.

\section{Complementary and Alternative Medicine (CAM) in NHS}

As per the study, there are only two forms of CAM which are registered and regulated by the NHS. The practice of chiropractic is regulated by the General Chiropractic Council (GCC) while osteopathy runs under the General Osteopathic Council (GOC). Patients are also referred to the other forms of CAM such as homeopathy, acupuncture and clinical hypnotherapy but such practices are not supervised by the NHS. Nonetheless, the practitioners are expected to hold set standards of qualifications and should be affiliated with an independent regulatory institution. NHS, on its official website under the section of CAM, provides all the terms and conditions for the practitioners for public consultancy. Furthermore, the White Government Paper for the Regulation of Health Professionals in the 21st Century is also available on the website of the General Regulatory Council for Complementary Therapies (GRCCT).

\section{Traditional Medicine as the First Choice of Medicine}

A considerable number of the participants mentioned that traditional medicine is their first choice of medicine. These participants stated that they take biomedicine as a secondary option for the following reasons.

i. Biomedicine is not prioritized because of its known sideeffects. 


\section{Annals of Social Sciences \& Management studies}

ii. Folk medicine specifically based on kitchen items like spices and eatables are non-harmful as they are part of routine life.

iii. There is an unexpected delay in arranging doctor's appointments and seeking medical advices whereas folk and traditional medicines are quick. Following points A and $\mathrm{B}$, it was evident that there is a perception that, unlike biomedicine, traditional medicine does not have adverse effects, whereas there is lack of literature and enough studies to claim traditional medicines as less or not harmful.

\section{Limitations of CAM}

The scientific revolution, in the early sixteenth century, introduced advanced forms of medical and surgical practices for the maintenance of quality of health. It is important to note that not every westerner was aware of these forms of medicine; rather it was popular amongst the elite and educated classes of the society [30]. The rest of the population continued the medicine which was traditional and indigenous to them. Hence, there were people in both, the Western and the Eastern parts of the World, unaware of the new forms of medical science and technology.

Later, the western knowledge and science of medicine sprung in all over the world during the colonial period. The coloniser from the West introduced the western medical sciences in colonies. Simultaneously, the coloniser specifically the military and administrators who lived in the colonies learnt about the medicine indigenous to those societies. With the movement of colonial power, these medicines also travelled across the western and eastern blocks of the world [23]. Since, the knowledge and access to the western medicine were limited to the elite class, military and state officials; it received special attention. It underwent constant research and advancement in the western world. Therefore, there is no doubt that doctors and practitioners are more certain about the uses and abuses of biomedicine and, it supports medical treatment where traditional medicine fails to cure.

\section{Therapeutic and Adverse Effects of Medicine}

“...that's the best thing about traditional medicine. Even if it does not help you; it won't harm you at all".

The comment made by two of the participants, as mentioned earlier, reflects that their preference of traditional medicine relies on a belief that the medicine does not have any side effect. There are several studies appreciating the therapeutic effects of traditional medicine. For example, the therapeutic effects of herbal medicine in treating cancer are well known [31,32]. Likewise, acupuncture is useful in treating the side-effects of drugs such as chemotherapy, anti-hypertensive and sedatives such as morphine [33-35]. Thus, traditional medicine tends to show a therapeutic effect in most of the cases; and so, it can be a preferable option for most of the participants in this study.

There exists another perception wherein traditional medicine does not have any adverse effect. Beside participants, literature also claims that it is a shared belief that traditional medicine does not have any side effects $[36,37]$. In addition, in most of the cases, health care providers are also not well-informed about the adverse-effects of traditional medicine used by their patients [38]. Perhaps, for this reason, the World Health Organisation (2000) clearly instructs every health authority to investigate the use of traditional medicine among patients and investigate the details for its legitimacy. Indeed, WHO $(2002,2013)$ present that the various programs are installed, and guidelines are published to mentor the safe utilisation of CAM.

\section{Personal Preferances}

The choices and personal preferences of participants in this study to when to prefer CAM over biomedicine was dependant of very intriguing factors.

i. For most of the participants, they prefer CAM for themselves or their spouses but not children. Children are vulnerable and have weak immune system therefore with less information on the side effects of CAM, parents keep biomedicine as their first choice. Nonetheless, there are studies in medical research on the proven benefits of CAM among pediatric patients [39-41]. In the context of the UK, Posadzki et.al [18], reports that the literature review of the utilisation of CAM suggests that almost half of the UK adults have administrated CAM to their children with elevated level of satisfaction.

ii. Though not always consciously; some of the responses of the participants project that their choice of medicine is associated with their personality type, personal and collective identity. For instance, a person said, "I am actually an 'allopathic person'. I do not try homeopathy or something else. I am kind of person who likes to stick with one thing that suits me". Identifying herself as 'allopathic person' indicates personal association and faith in one form of the medicine over others.

iii. A couple of participants kept their choice of medicine on the availability of information. For every home remedy that their parents suggest, they investigate. If they find enough information than they prefer traditional or folk medicine over biomedicine. By bringing the notion of knowledge and research in the selection of medicine, the general assumption of people that traditional medicine is practised blindly is challenged.

iv. The choice of medicine also depends on an individual's role in the family especially for women. A few participants found traditional and folk remedies very helpful in reducing illnesses and keeping their finances low. A participant said that "I am on the guard. I won't let anyone catch an infection". To keep her family members healthy, she keeps learning and investigating ways to avoid and cure illnesses at home.

\section{Culture, Society and Medicine}

A form of medicine, in this study, also came up as a symbol of identity for a group. When a group or a population stay closely tied 
to any specific healing practise, it becomes their identity marker $[5,6]$. This argument was reflected when quite a few participants mentioned that "traditional medicine is our culture. 'Other' people neither believe in 'our' medicine nor do they understand 'our' illnesses". The process in which people define themselves as part of an 'us' in opposition to a 'them' or an 'other' is called as ethnic identification [42]. People and communities take ownership of their medicine which then gradually turns out to be an ethnic marker for them.

However, the urge of maintaining an identity often becomes in the formation of ethnic boundaries where a group stay collided with the members of own community and separating own community from the other community [43]. If medicine is a way of creating an identity then simultaneously, it may function as a boundary between ethnic groups. At this point, one may debate on the 'cosmopolitanism' of biomedicine against the 'idiosyncrasy' of traditional medicine. This raises a question why do Pakistani migrants not only rely on traditional medicines to uphold their ethnic identity in Western countries such as the UK? Concurrently, a question arises on the role of biomedicine in the promotion of medical pluralism.

The other important factor is the collective medical experiences. The basic unit of Pakistani society is the family rather an individual. It is the duty of the family to look after the well-being of each other (Chaudhry, 1984). Also, as a religious value, Muslims consider it as an obligation to help and support those who are not keeping well. In such circumstance, the first ones to extend their supports are elderly members of the families and their experiences determine the choices of medicines. Also, stories and experiences of illnesses and medical treatments, in such collective societies, travel faster and farther. Most of the participants mentioned that they seek medical advices from their mothers and mothers-in-law back home as their experiences are integral to decide a form of medicine.

\section{Gender and The Choice of Medicine}

The maintenance of health of citizens in a country depends upon certain socio-economic and cultural factors. Some of the factors include the extent of poverty, illiteracy, unemployment and insufficient governmental initiatives in the health sector. All these factors are interrelated, and collectively, form a web where a person may find oneself trapped. These factors may affect men and women both. However, in certain societies like Pakistan, women face more challenges than men.

\section{Positionality of a Woman in Pakistani Families}

The Self-Rated Health (SRH) ratio between men and women in Pakistan is amongst the worst ratio found globally [8]. The ratio suggests that the health of women is three times worse than the health of men living in Pakistan. As mentioned earlier, the culture of Pakistan is collective. The values and needs of a family are prior to the values and needs of an individual. Extended family systems are common. Women, as daughter-in-law, live with family-in-laws and look after the need of every member of the family. A woman plays several roles in one time where her life is dedicated to the wellbeing and health of her family members and relatives. She is not autonomous and independent in making decisions [9]. Besides gender differences, the difference of age constricts the autonomy of a woman. Kadir et al. [13], informs that, in Pakistani societies, the influence of mothers-in-law overshadows the decision of husbands and male members of the family specifically in domestic matters. With such complex family structures, Pakistani women seek permission and opinions of other members of family while making any decision, including health care.

\section{Autonomy of Women in Decision Making Related to Health Care}

In contradiction to the fore mentioned literature, the Pakistani women who participated in the current study mentioned to take decisions related to family matters on their own. Indeed, they mentioned that their spouses and family members appreciate their role in decision making since they remain occupied with their work and matters outside the house. This imply some underlying factors. To start with, all the participants belonged to Karachi which is a highly urbanised metropolis of Pakistan. Urban locations provide space and opportunities to women where they exercise rights more easily in comparison to rural areas [44]. Even though urban areas also pose certain fears and vulnerabilities due to gender disparity; women enjoy recreational and social life more than women in rural areas. This reason may explain the authority of women in health-related matters. Another factor could be migration to a western country. A sizeable number of studies $[45,46]$, suggest that migration plays a vital role in transforming the socio-cultural including health behaviours of migrants. The social behaviors mainly change when couples or families move from a rural or a developing to an urban or a developed country respectively. Perhaps, the purpose behind adapting new culture could be adjustment in the host society; but it does transform their health behaviors [47-49].

\section{Conclusion}

Medicine is not a novel need of the human being as it has always been in function to freed people from illnesses and diseases. However, its form and politics is ever changing. With the advent of each civilisation, there are some advancement in the approaches, learning and practices of medicine. The social processes such as migration have helped these civilisations to exchange, borrow and appropriate medical knowledge and practices in their contexts. This way medical field is getting pluralist. Nonetheless, the disequilibrium of power between medical systems challenges the idea of pluralism. Each medicine tries to seize its place in the society and to overtake the hegemony of others. In current time, biomedicine dominates the status of traditional medicine at state level; however, both forms of medicine together are addressing the medical needs and demands of people. Though medical pluralism increases the medical choices and options for people; there are certain consequences which need to be regulated either by global 


\section{Annals of Social Sciences \& Management studies}

health agencies such as the World Health Organisation or national health systems. People living in the UK, including migrants, are free to choose any form of medicine.

However, if medical pluralism is the liberty of selecting a medicine; then unfortunately, there is not enough attention and efforts at state level in developed countries like UK where knowledge on CAM is equally available, well-researched and confidently presented to people as biomedicine. There is no way to determine individual's choice of a medicine; therefore, the best and safe practices is to expand information and knowledge on all forms of medicines so that choices are made wisely and without hesitation. This will also increase the affordability, accessibility and satisfaction of individuals on healthcare services.

\section{References}

1. Berry JW, Trimble JE, Olmedo EL (1986) Assessment of acculturation. In WJ Lonner, JW Berry (Eds.), Cross-cultural research and methodology series. California: Sage Publications, USA, 8: 291-324.

2. Palinkas LA, Pickwell SM (1995) Acculturation as a risk Factor for Chronic Disease Among Cambodian Refugees in the United States. Social Science Medicine 40(12): 1643-1653.

3. Herbert J Gans (1979) Symbolic Ethnicity: The Future of Ethnic Groups and Cultures in AMERICA. Ethnic and Racial Studies 2(1): 1-20.

4. Thomas J, Csordas (1990) Embodiment as a Paradigm for Anthropology. Ethos 18(1): 5-47.

5. Csordas TJ (2002) Body/Meaning/Healing. Palgrave, Macmillan, UK.

6. Kayne SB (2009) Introduction to Traditional Medicine. Traditional Medicine: A Global Perspective (Kayne, ed.). Pharmaceutical Press, London, UK, p. 1-24.

7. Joralemon D (1999) Exploring Medical Anthropology. Reno: Allyn \& Bacon, France.

8. Ahmad K, Jafar T, Chaturvedi N (2005) Understanding gendered influences on women's reproductive health in Pakistan: Moving beyond the autonomy paradigm. BioMed Central Public Health 5:51.

9. Mumtaz Z, Salway S (2009) Understanding Gendered Influences on Women's Reproductive Health in Pakistan: Moving Beyond the Autonomy Paradigm. Social Sciences and Medicine 68(7): 1349-1356.

10. Saleem S, Bobak M (2005) Women's autonomy, education and contraception use in Pakistan: A national study. Reproductive Health 2: 8

11. Rahman A (2004) Mothers' mental health and infant growth: a case-control study from Rawalpindi, Pakistan. Child: Care, Health \& Development 30(1): 21-27.

12. Shaikh BT, Hatcher J (2005) Health Seeking Behaviour and Health Service Utilization in Pakistan: Challenging the Policy Makers. Journal of Public Health 27(1): 49-54.

13. Kadir M, Fikree F, Khan A, Sajan F (2003) Do mothers-in-law matter? Family dynamics and fertility decision-making in urban squatter settlements of Karachi, Pakistan. Journal of biosocial science 35(4): 545-558.

14. Rienzo C, Vargas-Silva (2012) Migrants in the UK: An overview. Migration Observatory Briefing. University of Oxford, Oxford, England.

15. National Health Services (2018) The National Health Survey. Office for National Statistics, UK.

16. Piggott G (2005) 2001 Census Profiles: Pakistanis in London. Data Management and Analysis Group, London, UK.
17. Brady E (2001) Integrating Personal Health Belief Systems. Healing Logics. Logan: Utah State University Press, US, pp. 115-128.

18. Posadzki P, Watson LK, Ernst E (2013) Adverse effects of herbal medicines: an overview of systematic reviews. Clinical Medicine 13(1): 7-12.

19. Smith (2009) Some traditional umbilical cord care practices in developing countries. Midwifery Today International 91: 12-13.

20. World Health Organization (2002) Traditional Medicine - Growing Needs and Potential. Traditional Medicine. WHO Policy Perspectives in Medicine. World Health Organisation, Geneva, Europe.

21. Kleinman A (1980) Patients and Healers in the Context of Culture: An Exploration of the Borderland Between Anthropology, Medicine, and Psychiatry. University of California Press, Berkeley, US.

22. Ernst W (2002) Plural Medicine, Tradition and Modernity, 1800-2000. Ernst (Ed.), Routledge, London, UK.

23. Baer HA, Singer M, Susser I (2003) Medical Anthropology and the World System $\left(2^{\text {nd }} e d n\right)$. Westport: Praeger Publishers, UK.

24. Foster GM (1976) Disease Etiologist in Non-Western Medical Systems. American Anthropologist 78(4): 773-782.

25. Ramsey M (1988) Medical Pluralism in early modern France. Medical Pluralism: Past-Present-Future (Robert Jutt. Ed.). Franz Steiner Verlag, Berlin, Germany. pp. 57-80.

26. Strathern A, Stewart PJ (1999) Curing and Healing: Medical Anthropology in Global Perspective. Carolina Academic Press, Virginia, US.

27. Change Institute (2009) The Indian Muslim Community in England Understanding Muslim Ethnic Communities. London: Communities and Local Government, UK.

28. National Health Services (2015) The NHS Constitution for England. Department of Health and Social Care, UK.

29. Campbell D (2013) Shortage of hospital beds and staff 'forcing patients to sleep in corridors. London: The Guardian News, UK.

30. Nutton V (2003) Medicine (CT). Leiden, Koninklijke Brill NV, Europe.

31. Meng QX (2013) Ethnopharmacological and bioactivity guided investigation of five TCM anticancer herbs. Journal of Ethnopharmacology 148(1): 229-238.

32. Jeong SJ, (2011) Are there new therapeutic options for treating lung cancer based on herbal medicines and their metabolites? Journal of Ethnopharmacology 138(3):652-661.

33. Salmon J, (2013) Evaluation of an acupuncture service in oncology Journal of Radiotherapy in Practise 12 (1): 39-55.

34. Cevik C, Iseri S (2013) The effect of acupuncture on high blood pressure of patients using antihypertensive drugs. Acupuncture and ElectroTherapeutics Research 38(1-2): 1-15.

35. Jiang (2011) Anti-inflammatory effects of electroacupuncture in the respiratory system of a symptomatic amyotrophic lateral sclerosis animal model. Neuro-Degenerative Diseases 8(6): 504-514.

36. Mathew (2013) Self-Reported Use of Complementary and Alternative Medicine among the Health Care Consumers at a Tertiary Care Center in Ajman, United Arab Emirates. Annals of Medicine and Health Science Research 3(2): 215-219.

37. Marian F (2008) Patient Satisfaction and Side Effects in Primary Care: An observational Study Comparing Homeopathy and conventional Medicine. International Society for Complementary Medicine Research 8: 25 .

38. Lanski SL, Greenwald M, Perkins A, Simon HK (2003) Herbal Therapy uses in a Paediatric Emergency Department Population: Expect the Unexpected. Paediatrics 111(5): 981-985. 


\section{Annals of Social Sciences \& Management studies}

39. Fixsen D, Blase K, Metz A, Van Dyke M (2013) State-wide Implementation of Evidence-Based Programs. Exceptional Children 79(3): 213-230.

40. Gottschling S, Meyer S, Längler A (2014) Differences in Use of Complementary and Alternative Medicine Between Children and Adolescents with Cancer in Germany: A Population-Based Survey. Paediatric Blood Cancer 6(3): 488-492.

41. Singendonk M (2013) High prevalence of complementary and alternative medicine use in the Dutch pediatric oncology population: A multicenter survey. European Journal of Pediatrics 172(1): 31-37.

42. Karlsen S, Nazroo JY (2009) Religion, ethnicity and health inequalities. Understanding Health Inequalities $\left(2^{\text {nd }}\right.$ edn. H. Graham). Open University Press, London, UK.

43. Barth F (1969) Ethnic Groups and Boundaries: The Social Organization of Culture Difference. Norway: Universitetsforlaget, Europe.

44. Bird SR, Sapp SG (2004) Understanding the Gender Gap in Small Business Success: Urban and Rural Comparisons. Gender and Society 18(1): 5-28

This work is licensed under Creative Commons Attribution 4.0 License DOI: 10.19080/ASM. 2018.02.555581
45. Braw A, Harigaya T (2007) Seasonal Migration and Improving living Standards in Vietnam. American Journal of Agricultural Economics 89(2): 439-447.

46. Jensen ER, Ahlburg DA (2004) Why does Migration Decrease Fertility? Evidence from the Philippines. Population Studies 58(2): 219-231.

47. World Health Organization (2000) General Guidelines for Methodologies on Research and Evaluation of Traditional Medicine. World Health Organisation Headquarters, Geneva, Europe. pp.1-74.

48. World Health Organization (2013) WHO Traditional Medicine Strategy 2014-2023. World Health Organisation, Geneva, Europe.

49. Zhou X (2010) Development of traditional Chinese medicine clinical data warehouse for medical knowledge discovery and decision support. Artificial Intelligence in Medicine 48 (2-3): 139-152.

\begin{tabular}{|l|}
\hline \multicolumn{1}{|c|}{ Your next submission with Juniper Publishers } \\
will reach you the below assets \\
- Quality Editorial service \\
- Swift Peer Review \\
- Reprints availability \\
- E-prints Service \\
- Manuscript Podcast for convenient understanding \\
- Global attainment for your research \\
- Manuscript accessibility in different formats \\
( Pdf, E-pub, Full Text, Audio) \\
- Unceasing customer service \\
Track the below URL for one-step submission \\
https://juniperpublishers.com/online-submission.php \\
\hline
\end{tabular}

